FACTA UNIVERSITATIS

Series: Mechanical Engineering Vol. 16, $\mathrm{N}^{\mathrm{o}} 2$ 2, 2018, pp. 261 - 272

https://doi.org/10.22190/FUME170512022K

Original scientific paper

\title{
A THERMAL ANALYSIS OF THE THREADED SPINDLE BEARING ASSEMBLY IN NUMERICALLY CONTROLLED MACHINE TOOLS
}

\author{
UDC 621.8
}

\author{
Vladislav Krstić, Dragan Milčić, Miodrag Milčić \\ Faculty of Mechanical Engineering, University of Niš, Serbia
}

\begin{abstract}
A threaded gear in machine tools is a mechanical actuator that converts rotary motion into linear one of the machine axis using a recirculating ball-nut. It provides positioning accuracy, uniform motion, silent operation, reduced wear and an increased service life. The bearing assembly of the threaded spindles should provide load transfer (cutting forces and friction forces) while maintaining high guiding accuracy. Due to a high number of the threaded spindle revolutions and the presence of tension in the bearing and a high axial force originating from the cutting and friction forces, the increased heat load due to friction in the bearings is normally expected. For this reason, this paper presents a thermal analysis of the bearing assembly of the threaded spindle which is realized via an axial ball bearing with angular contact of the ZKLN type, produced by the German manufacturer Schaeffler (INA); in other words, a numerical thermal analysis has been performed.
\end{abstract}

Key Words: Threaded Spindles, Bearing, Thermal Analysis, Thermal Load

\section{INTRODUCTION}

Automation of small-batch and batch manufacturing as the dominant type in the metal processing industry is successfully carried by means of numerically controlled machine tools. They are characterized by increased productivity and accuracy. In machine tools there are a number of local heat sources that increase the thermal gradient inside the machine: an electric motor, friction in the mechanical drive and gears, processing, ambient temperature. Heat sources cause local deformations, affecting machine accuracy. Therefore, the drive (motor and mechanical gear) should be mounted on the outside of the machine; the temperatures resulting from friction in the bearings and sliding spindle

Received May 12, 2017 / Accepted February 05, 2018

Corresponding author: Dragan Milčić

Faculty of Mechanical Engineering, University of Niš, A. Medvedeva 14, 18000 Niš, Serbia

E-mail: dragan.milcic@masfak.ni.ac.rs 
should be eliminated by adequate lubrication, the temperature generated during processing should be eliminated by adequate cooling and metal shavings removal system, and machine structure should be realized in accordance with the thermally-symmetrical design. Mechanical gear may be: threaded gear (threaded spindle and nut), spur (sprocket) gear (pinion and rack) and timing (toothed) belt gear or chain gear.

The most commonly used mechanical gear in machine tools is a threaded gear consisting of a threaded spindle and a nut. The main task of the threaded spindle in machine tools is to convert the machine axis motion from rotational into linear one using a recirculating ball-nut. The threaded spindle rotates with high speed. The ball thread and the nut have precision-made helical grooves through which the balls circulate and thus provide a very high degree of guiding accuracy ensuring the final product quality. The bearing assembly of threaded spindles is one of the most challenging tasks in mechanical engineering. The threaded spindles are loaded with a high axial force originating both from processing, i.e. cutting forces, and from frictional forces, and that load must be received by the bearing assembly. Fig. 1 (on the right) shows an example of the threaded spindle of the machine tool in the bearing assembly.

Due to the rolling friction at the joint between the threaded spindle and the nut and in the rolling bearings, heat load is generated in the bearing assembly of the threaded spindle. The generated amount of heat induced by friction between the nut and the spindle, as well as friction in the bearing itself, affect the elongation of the spindle, further leading to errors in the guidance which ultimately leads to poor quality products.
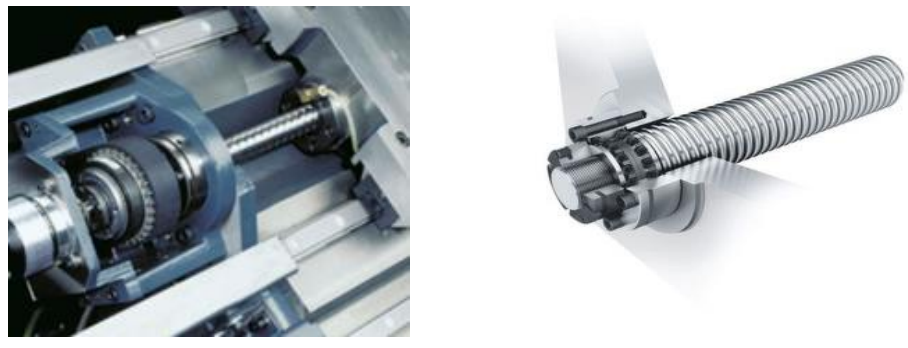

Fig. 1 Threaded spindle of the machine tool

\section{OVERVIEW OF THE PREVIOUS WORK}

With the expansion of CNC machines the volume of research has increased regarding the problem of heat generation due to friction in the drive part of the machine tools (threaded gear) and the impact on the precision of the machine tools.

Mahmmod [1] in his work focuses on heat generation due to friction induced forces that occur in the threaded spindle and the associated ball-nut. The paper gives an explanation of the phenomenon of heat accumulation that could affect the occurrence of positioning errors due to the main elongation. The deformations caused by temperature increase are estimated based on the temperature distribution to the threaded spindle and the nut, and a conventional finite difference method is obtained.

Zahedi and Movahhedy in their work [2] contributed to the development of a comprehensive model of high speed spindles that includes sustainable models for mechanical and thermal behavior of its main components, i.e. bearings, shaft/axle and housing. The spindle 
housing and the shaft are modeled as elements of the Timoshenko beam model in the form of six degrees of freedom. The bearings are modeled as two-node elements with five positions and a component of thermal load in each node. Interaction between thermal and structural behavior of the spindle, housing, bearing and shaft, is described by means of thermal expansion and range of heat transfer. The components are combined in the form of the finite elements model for thermo-mechanical analysis of the spindle-bearing system.

In order to obtain thermal characteristics of the integrated spindle-bearing system in CNC machines, Xiaolei et al. [3] have defined a mathematical model, using the heat source model. Heat characteristics of the spindle-bearing system are identified using the derived formulas and as such were inserted into the model, which was tested by the finite element method. Four different cases with different amounts of heat were tested, different coefficients of heat transfer as well as the geometric dimensions of the model and the position of the heat sources. Using this model on two real systems in practice, the prediction of the thermal field was performed and later results obtained using the model and through concrete temperature measurement were compared. The maximum relative error for both systems was $0.41 \%$ and $8.38 \%$, respectively.

Takafumi et al. [4] in their work gave an analysis of the deformation of rolling elements i.e. balls, as well as the heat generation that occurs in the axial ball bearing with an angular contact surface intended for the threaded spindle bearing assembly in machine tools. They conducted a three-dimensional measurement of movement of the balls, and proposed construction of the axial ball bearing with angular contact, inner diameter of $70 \mathrm{~mm}$, an outer diameter of $110 \mathrm{~mm}$, for the operating speed of $n=30000 \mathrm{~min}^{-1}$.

Xiao et al. [5], focus on the study of sources of heat that is generated by the spindle of the $\mathrm{CNC}$ machine, which works with a high number of revolutions. The whole research was based on a model of thermo-mechanical coupling.

Yang and Wanhua in their work [6] elaborate methods of compensation of axial error caused by thermal load on the spindle in machine tools.

Wang et al. provide research [7] of effects of the inner ring displacement due to the effect of centrifugal forces on the dynamic characteristics of ball roller bearings with angular contact, designed for high speeds.

Yasushi in his work [8] gave a description of the status and trends for the support and improvement of high speeds in machine tools. He also made reference to the new ceramic materials with very good friction properties, which further supports the increase in the number of the bearing revolutions, while reducing friction in the same, thereby reducing the generated heat load.

Yukio et al. [9] give a presentation of so-called "Robust" batch of bearings. This type of bearing is intended to increase productivity with lower power consumption, which is very important in terms of energy efficiency, which has been a popular topic for many years.

$\mathrm{Wu}$ and Tan [10] have developed a thermo-mechanical coupling analysis model of the spindle-bearing system based on the Hertz's contact theory and the point contact nonNewtonian thermal elastohydrodynamic lubrication (EHL) theory.

Kumar and Rao [12] have considered previous experimental and analytical work, a static-thermal finite element analysis (FEA) of a railroad bearing pressed onto an axle and analyzed using the ANSYS.

The manufacturer of the threaded spindles "HEIDENHAIN" from Germany in its publication [19] provides a detailed description and explanation of possible problems regarding 
the threaded spindle operation. It also presented a description of possible impacts that lead to guidance errors. All these impacts are divided into two main groups, one comprising guidance errors due to mechanical influences while the other comprises those induced by thermal loads. The publication offers concrete solutions for compensation and monitoring of errors during the threaded spindle operation. These solutions range from the simplest options of installing measuring laths, through the structure of the threaded spindle itself to expensive software solutions for continuous monitoring of operation.

\section{BEARING ASSEMBLY OF THREADED SPINDLES AND CONSTRUCTION OF ZKLN TYPE BEARINGS}

A bearing assembly of threaded spindles is generally resolved in practice in several ways depending on the particular constellation of mechanical system and the expected load.

As shown in Fig. 2, there are three ways of bearing assembly of threaded spindle (from the top down), i.e.: free/fixed bearing, fixed/fixed bearing and fixed/fixed and prestressed bearing. The third case of bearing assembly is the most demanding because bearing is fixed on both sides, where the bearing is on the right support (additionally prestressed) for achieving increased rigidity and better compensation of the axial forces. Because of the present tension in the axial direction during operation increased friction will occur that generates a larger amount of heat, which in turn affects the thermal dilatation of both the bearing assembly and the threaded spindle, thereby endangering the accuracy of guidance. For this reason it is very important to better define the thermal load of the bearing assembly, as early as in the design stage, taking into account all relevant impacts that will be present during the operation in order to compensate axial errors of the threaded spindle as much as possible.

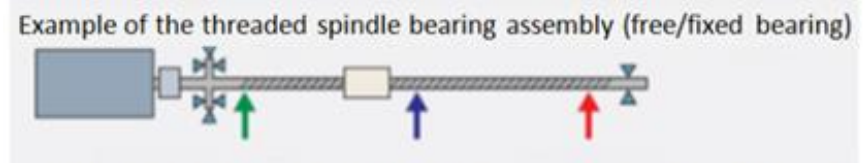

Example of the threaded spindle bearing assembly (fixed/fixed bearing)

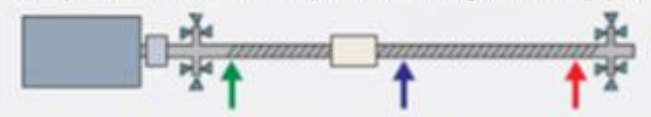

Example of the fixed prestressed threaded spindle bearing assembly (free/prestressed bearing)

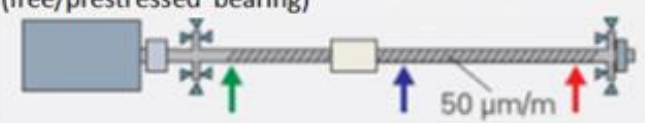

Fig. 2 Basic types of bearing assemblies of threaded spindles [19]

In general case, the type of bearing assembly with free/fixed bearing will be used at shorter threaded spindles when greater axial rigidity of the system is not required and when the critical rotational speed of the threaded spindle is high enough. The type of bearing assembly with fixed/fixed bearing is recommended for medium and longer threaded spindles when the system requires high axial rigidity when a critical number of revolutions of the threaded spindle is high, and when a smaller effect of changes in length due to heating is 
expected on positioning. The type of bearing assembly with fixed/fixed and prestressed bearing is recommended in the case of long threaded spindles, in high dynamic threaded spindles when greater longitudinal deformation of the threaded spindle is expected.

For bearing assemblies of threaded spindles, the German manufacturer Schaeffler has designed special bearings for this purpose. In fact, these are axial ball bearings with an angular contact of ZKLN and ZKLF types. As an example, the ZKLN2557-2Z type of bearing will be analyzed in this paper, produced by the German manufacturer Schaeffler (INA).

In order to better understand the analysis of this bearing, we must firstly inspect its structure. During the threaded gear operation, the maximum load is generated from the associated recirculation nut, which slides over the spindle. Theoretically, the threaded spindle bearing assembly receives radial and axial load, but axial load is much higher (over 90\%), and for that reason the structure of this bearing is adjusted to this fact. The specificity of the ZKLN type bearing is a two-piece inner ring, and a much wider angle of contact between the rolling body-balls and the rolling track (an angle of $60^{\circ}$ ). In addition, this bearing has a precision nut for prestressing the bearing and also a cover through which the bearing is further secured to the machine housing, and all in order to secure the bearing in the axial direction. From the above-mentioned structure of the bearing, a significant heat load of the bearing assembly can be expected at higher speeds.

Figure 3 presents the case of installing the ZKLN type bearing. Basically this type of bearing does not provide, in its design, any additional bolted connection used for fixing to the housing of the machine. For this reason, its securing is realized using a precision nut for prestressing and cover, which is further secured to the machine housing through the bolted connection.

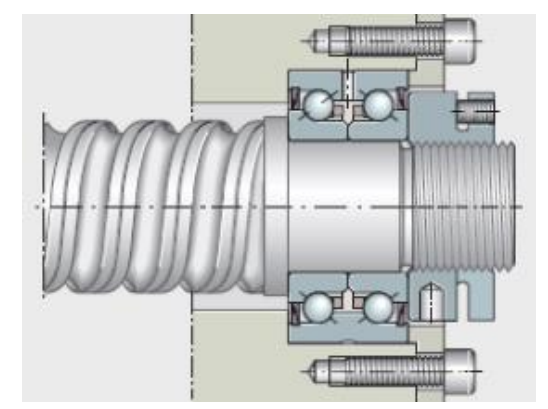

Fig. 3 The case of installation of the bearing of ZKLN type [13]

ZKLN2557-2Z bearing, produced by Schaeffler (INA) [13], was used as a representative for thermal analysis.

\section{THERMAL LOAD ON THE THREADED SPINDLE BEARING ASSEMBLY}

For thermal analysis of the bearing of the ZKLN type it is necessary to define thermal load of the bearing.

Thermally safe operating speed $n_{\vartheta}$ is calculated according to DIN $732[14,15]$. The basis for the calculation is the heat balance in the bearing, the equilibrium between the frictional 
energy as a function of speed and the heat dissipation as a function of temperature. When conditions are in equilibrium, the bearing temperature is constant. The permissible operating temperature determines thermally safe operating speed $n_{\vartheta}$ of the bearing. For calculation, it is assumed that normal operating clearance and constant operating conditions are present. In addition to the thermally safe operating speed, limiting speed $n_{G}$ must always be observed.

The essential operating conditions are:

- Reference temperature of the ball bearing on stationery outer ring $70^{\circ} \mathrm{C}$,

- Reference temperature of the ball bearing environment $20^{\circ} \mathrm{C}$,

- Reference load for axial ball bearings for threaded spindles equals $2 \%$ of static load of the bearing for axial bearings with contact angle $45^{\circ}<\alpha<90^{\circ}$ [18]. The contact angle by ZKLN type is $60^{\circ}, P_{1 r}=0,02 \cdot C_{0}$.

It should also be noted that the standard DIN 732, part 1 and part 2 , will be only partially applicable for the entire analysis. The reason for this is the specific structure of the aforementioned bearing. Specifically, the standard covers only standard bearing structures in which the maximum angle of contact is $40^{\circ}$, and at the same time the bearings in their structure do not include bolted connection, cover, precise nut for prestressing and housing to which the bearing will be further secured.

In order to properly perform the analysis, it is necessary to comply with all the theoretical basics related to the mechanisms of heat transfer. As is already known, there are three ways to transfer heat: conduction, convection and radiation.

For easier understanding, Fig. 4 represents a simplification of the transfer of heat through the observed system of bearing assembly (in case of installation of the bearing of ZKLN type).

As can be seen from Fig. 4, the thermal energy that occurs in the bearing assembly is at first induced on the surface between the rolling elements and the rolling track and then spreads in the directions as shown by the arrows in the same Fig. 4 [13].

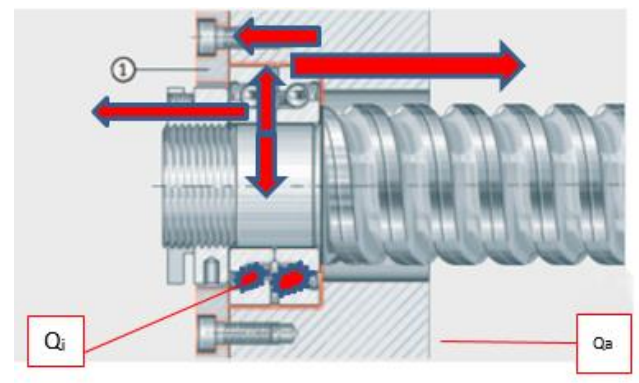

Fig. 4 Schematic representation of the propagation of heat in the bearing assembly

( 1 - cover for additional securing to the machine housing, $Q_{i}$ - generated amount of thermal energy, $Q_{a^{-}}$amount of thermal energy discharged) [13]

The entire thermal process for the present case is divided into several branches. One branch describes the movement of generated thermal energy through the bolt, over the contact surface of the cover for additional bearing/housing securing and out into the environment. On this path the thermal energy passes through "solid material" and the contact surface. The next branch shows the movement of thermal energy through "solid material" of the outer ring of the bearing and bolt. Here, it is shown that the heat energy passes through the "solid material" but also 
through the bearing/housing contact surface. The next branch shows the movement of thermal energy from the rolling track and the rolling body through the inner ring, the contact surface (inner ring/ bearing prestressing nut) and further into the atmosphere. The last branch describes the flow of thermal energy from the rolling track and the rolling body over the inner ring and the contact surface (inner ring/threaded spindle) and ends at the threaded spindle.

The main internal heat transfer mechanisms are: transfer of heat between the rotational elements of bearings, transfer of heat from the stationary bearing elements and conduction between the contact elements of the bearing (Fig. 5).

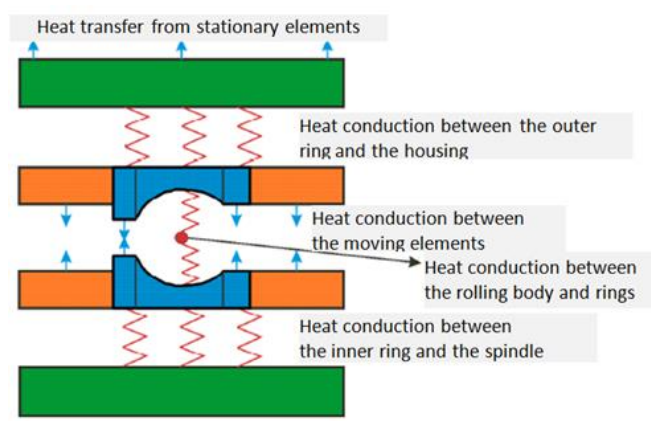

Fig. 5 Heat transfer mechanisms in the bearing [11]

\section{THE CONCEPT OF THERMAL ANALYSIS OF THE THREADED SPINDLE BEARING ASSEMBLY}

For the reasons of great complexity of the system, the thermal analysis will be conducted through simulation for the bearing of ZKLN2557-2Z type [13]. Hereinafter, for this type of bearing the abbreviated notation (ZKLN) will be used. Hereafter follows the algorithm of the concept of performed simulation, see Fig. 6.

The Fig. 6 presents an algorithm of thermal analysis of the threaded spindle bearing assembly. The thermal analysis is done in an iterative process as a combination of the analytical procedure of determination of the power loss due to friction in the bearing, which is converted into heat generated in the bearing and numerical calculation for determining the temperature field of the threaded spindle bearing assembly.

As an input for determining power losses due to friction according to the DIN 732-1 we used geometry of the selected ZKLN bearing and limiting speed $n_{G}=2350 \mathrm{~min}^{-1}$ for that bearing which was given in the manufacturer's catalog [13]. The power loss due to friction between the rolling elements and the outer and inner rings of the bearing $N_{F r}$ is converted into heat $Q$ which is transferred through the outer or inner ring. For the purposes of thermal FEA analysis it is necessary to determine the heat flux at the outer and inner ring of the bearing. It is assumed that $75 \%$ of the heat is surrendered to the outer rolling path, and the remaining $25 \%$ to the inner rolling path. This is empirical data, based on experience of Schaeffler, i.e. internal recommendation for thermal distribution by bearing.

Based on the assessment of the propagation of heat through the bearing and further to the bearing assembly and based on the area of path of the inner and outer rings, the specific amount of heat, i.e. heat flux is determined. 
Based on the prepared model of the bearing in FEA software ABAQUS 6.9-3 numerical calculations, a thermal analysis is performed. For thermal analysis, a bearing assembly of the threaded spindle with ZKLN2557-2Z bearing was adopted as well as different materials of the bearing housing, made of steel, cast iron EN-GJL 250 (cast iron 25) and aluminum. Further presentation will present the results for the case of steel housing.

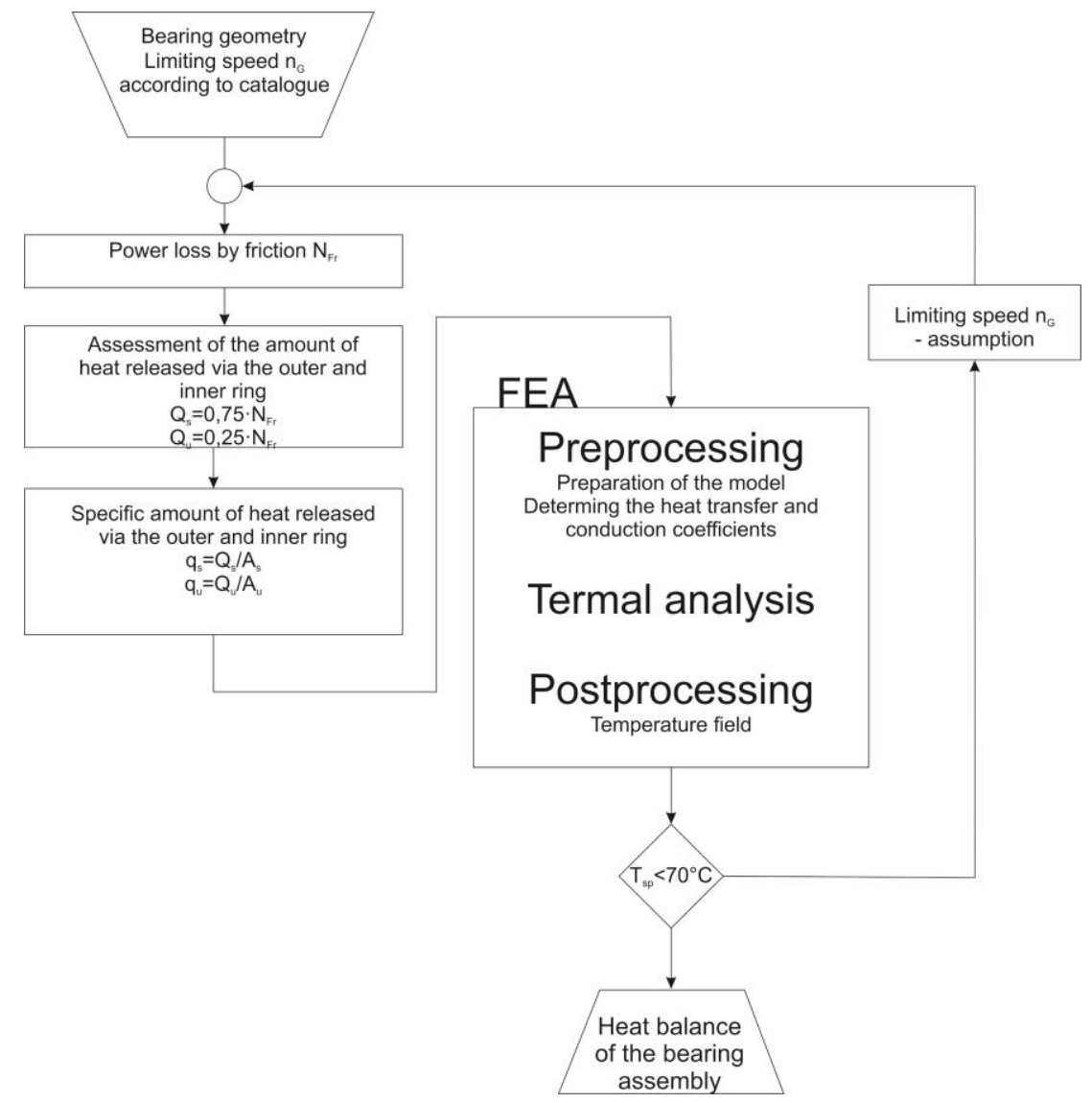

Fig. 6 Algorithm of thermal analysis of the threaded spindle bearing assembly

In the FEA thermal analysis, the simulation model is prepared in the preprocessing phase. The adopted model for the analysis is $2 \mathrm{D}$, and because of the symmetrical bearing assembly and symmetric impact of loads, we observed only half of the bearing assembly.

For the purposes of thermal analysis the values of the thermal conductivity coefficient within the system were calculated as well as the heat transfer coefficient by taking into account mechanisms of heat transfer. Fig. 7 provides the values of heat transfer coefficients $\alpha$ with appropriate speed $n$ and temperatures $T$ in certain parts of the system for the case of bearing assembly for the ZKLN2557-2Z bearing. 


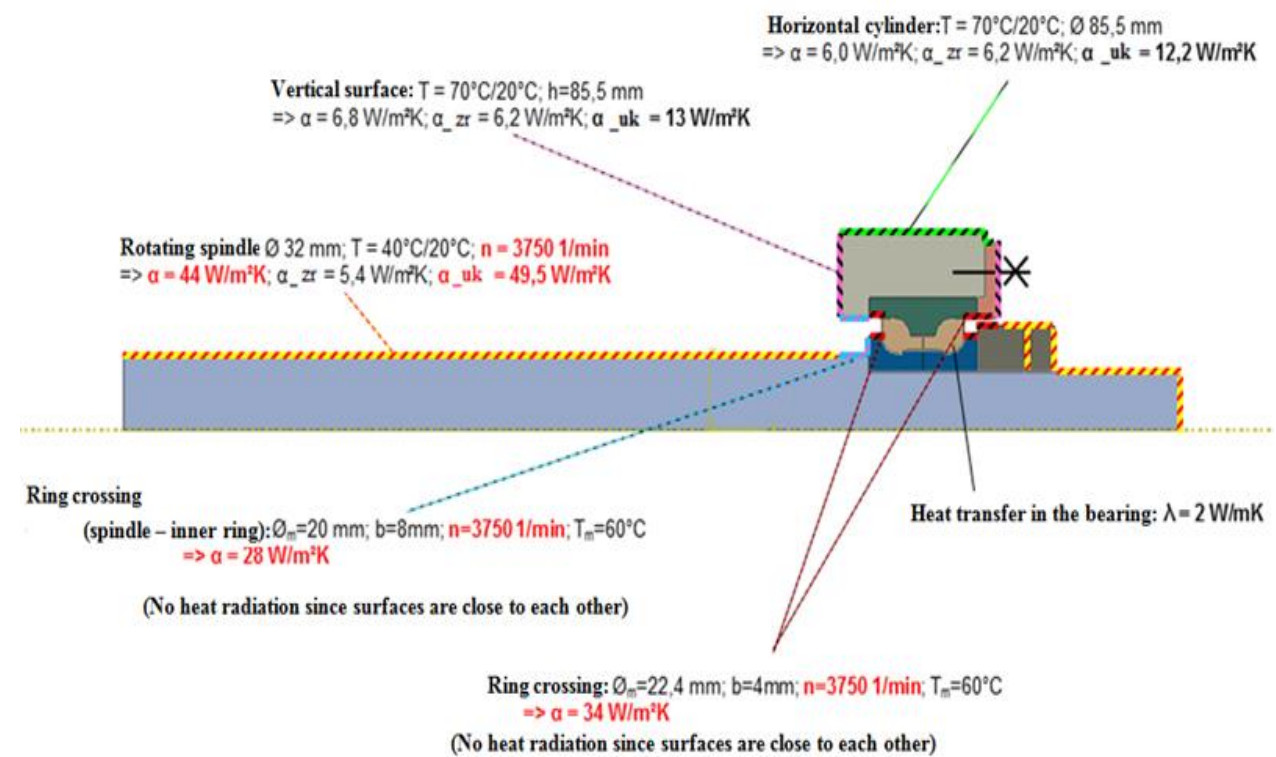

Fig. 7 Values of heat transfer coefficients for the case of bearing assembly of the ZKLN2557-2Z bearing

In determining the coefficient of heat transfer by radiation, the emissivity coefficient of dark surfaces $\varepsilon=0.8$ was adopted. Heat transfer coefficients (by convection) in general are defined in accordance with [17], see Equation 1:

$$
\alpha=\frac{N_{u} \cdot k_{\text {fluid }}}{D_{\lambda}}
$$

where $k_{\text {fluid }}$ is thermal conductivity in the case of heat transfer between the elements of the bearing in W/mK, $N_{u}$ is Nusselt's number (dimensionless value), $D_{\lambda}$ is diameter from which the heat is released in $\mathrm{m}$, and $\alpha$ is coefficient of heat transfer in $\mathrm{W} / \mathrm{m}^{2} \mathrm{~K}$.

For the purposes of thermal analysis it is also necessary to define the contact load of the bearing at the points of contact between the inner ring of the bearing - threaded spindle, the outer ring of the bearing - bearing housing, the inner ring of the bearing - bearing prestressing nut and bearing cover - bearing housing.

Figure 8 shows the contact load on the ZKLN2557-2Z bearing with the values of the contact pressure due to installing installation. It also shows the heat transfer coefficients for the existing contact surfaces. They serve as an equivalent for describing thermal resistance. 


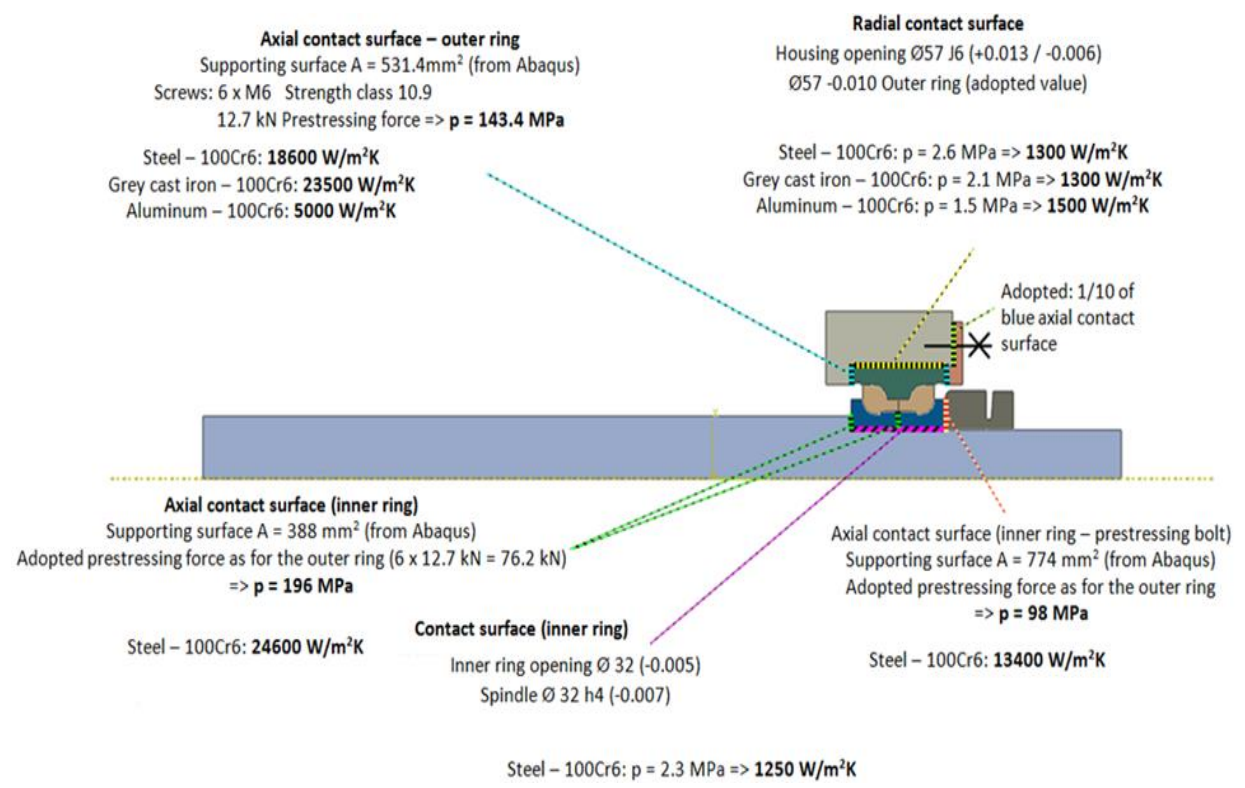

Fig. 8 The values of the load of the bearing on the contact surfaces in the case of bearing assembly of the ZKLN2557-2Z bearing

After preparing the simulation model in the preprocessing stage, the solver of the FEA software Abaqus gives a temperature field as a result. Figure 9 shows simulation results for the case of the first iteration for the steel housing.

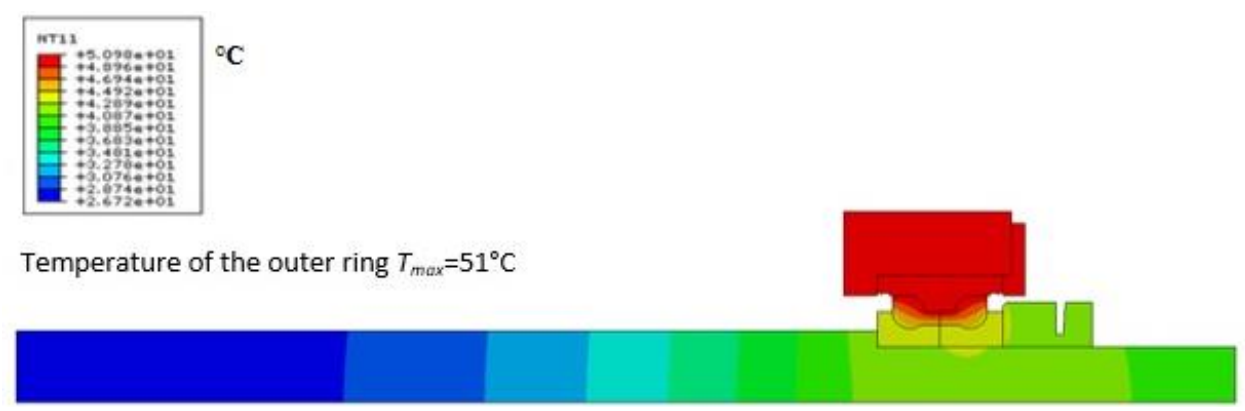

Fig. 9 Temperature field of the bearing assembly of the threaded spindle in case of steel housing

For the purposes of determination of the heat load of the threaded spindle bearing assembly, it is necessary that the temperature of the outer ring is $70^{\circ} \mathrm{C}$. For this reason, the second iteration is performed. The used number of revolutions of the bearing (threaded spindle) $n_{2}$ is greater than the number of revolutions used in the first iteration $-n_{2}=3500 \mathrm{~min}^{-}$ ${ }^{1}>n_{G}=2350 \mathrm{~min}^{-1}$ and the procedure from the algorithm in Fig. 6 is repeated. The procedure is repeated until the result of the FEA thermal analysis shows the temperature of the outer 
ring of the bearing of $70^{\circ} \mathrm{C}$ (reference condition). In the example analysis of the ZKLN2557$2 \mathrm{Z}$ bearing this case happened in the third iteration for the estimated number of revolutions $n_{3}=3750 \mathrm{~min}^{-1}$.

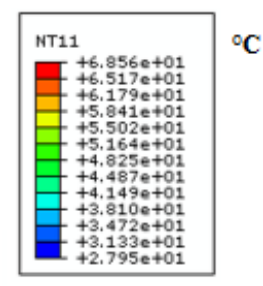

${ }^{\circ} \mathrm{C}$

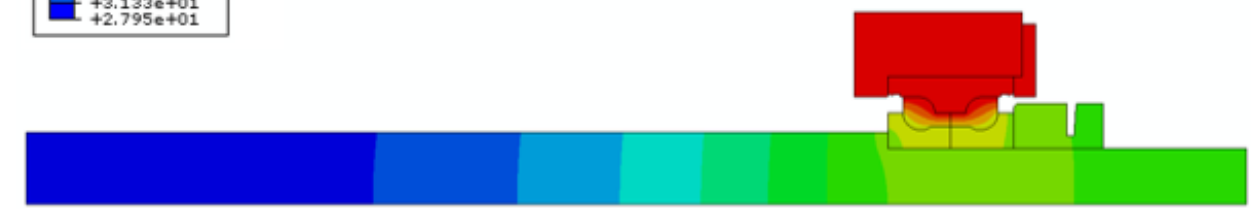

Fig. 10 Temperature field of the bearing assembly of the threaded spindle in case of steel housing - third iteration (the temperature of the outer ring $70^{\circ} \mathrm{C}$ )

Table 1 shows the results of the FEA simulation of the temperature of the outer ring of the bearing for different materials of the bearing housing. As shown in Table 1, neither the housing material nor the threaded spindle length significantly affects the temperature of the outer ring of the bearing, i.e. the heat distribution through the system (threaded spindle- bearing- housing- cover- precision nut for prestressing of the bearing).

Table 1 Temperature on the outer ring of bearing type ZKLN2557-2Z for different variations housing materials

\begin{tabular}{ccc}
\hline $\begin{array}{c}\text { Power loss by friction } \\
N_{f r} \text { in W }\end{array}$ & Housing materials & $\begin{array}{c}\text { Temperature on the } \\
\text { outer ring in }{ }^{\circ} \mathrm{C}\end{array}$ \\
\hline 36 & Steel housing & 68.6 \\
36 & Steel housing (bigger housing) & 65.6 \\
36 & Steel (smaller threaded spindle) & 69.7 \\
36 & Steel housing (increased axial & 65.2 \\
36 & removal of heat on the housing) \\
36 & Aluminum housing & 68.5 \\
36 & Cast iron EN-GJL 250 & 68.6 \\
\hline
\end{tabular}

\section{CONCLUSION}

A threaded gear in machine tools is a mechanical actuator that converts rotary motion into linear one of the machine axis using a recirculation ball-nut. The threaded gears primarily have to ensure positioning accuracy. The heat generated due to the rolling and sliding friction in the bearing and the recirculating nut affects accuracy of machine tools. For this reason, it is important to determine thermal load. This paper presents an algorithm 
for determining thermal load of the bearing assembly of the threaded spindle, which is of iterative nature and consists of combination of analytical and numerical FEA thermal analysis. This paper shows an example of FEA thermal analysis on the ZKLN2557-2Z bearing.

The main influential factor is the reference surface through which heat is transferred. That means that by other similar type of bearing (for example ZKLF) the heat distribution will be different because of the extended reference surface. Further, it means that this paper presents a new approach to the thermal analysis of the threaded spindle bearing assembly.

\section{REFERENCES}

1. Mahmmod, A., M., 2011, The effect of the heat generated by friction in the ball-screw-nut system on the precision of high speed machine, Journal Al-Taqani, 24(6), pp. 112-123.

2. Zahedi, A., Movahhedy, M.R., 2012, Thermo-mechanical modeling of high speed spindles, Scientia Iranica, 19(2), pp. 282-293.

3. Xiaolei, D., Jianzhong, F., Yuwen, Z., 2015, A predictive model for temperature rise of spindle-bearing integrated system, Journal of Manufacturing Science and Engineering, 137(2), pp.1-10.

4. Yoshida, T., Tozaki, Y., Omokawa, H., Hamanaka, K., 2001, Tribological technology. Threedimensional ball motion in angular contact ball bearing for high-speed machine tool spindle, JGLOBAL, 38(6), pp.304-307.

5. Xiao, S., Guo, J., Zhang, B., 2006, Research on the motorized spindle's thermal properties based on thermo-mechanical coupling analysis, Technology and Innovation Conference, ITIC, Hangzhou, China, pp. 1479-1483.

6. Yang, L., Wanhua, Z., 2012, Axial thermal error compensation method for the spindle of a precision horizontal machining, International conference Mechatronics and Automation, ICMA, pp. 2319 - 2323.

7. Wang, B., Mei, X., Hu, C., Wu, Z., 2010, Effect of inner ring centrifugal displacement on the dynamic characteristics of high-speed angular contact ball bearing, International conference Mechatronics and automation, ICMA, pp. 951-956.

8. Morita, Y., 2002, High speed and high precision enhancement technology of the bearing for the main spindle of machine tool, Journal Science of machine, F0147A, 54(9), pp. 935-940.

9. Oura, Y., Katsuno, Y., Sugita, S., 1999, Robust series high-speed precision angular contact ball bearings for machine tool spindles, Journal NSK Tech J, S0469A, 668, pp. 20-28.

10. Wu, L., Tan, Q., 2016, Thermal Characteristic Analysis and Experimental Study of a Spindle-Bearing System, Entropy, 18(7), 271; doi:10.3390/e18070271.

11. Živković, A., Zeljković, M., Tabaković, S., 2013, Software solution for the analysis of behavior ball bearings -Report (technical solution) (in Serbian), Faculty of Technical Sciences, University of Novi Sad.

12. Kumar, P.M., Rao, C.J., 2015, Structural and Thermal Analysis on a Tapered Roller Bearing, IJISET International Journal of Innovative Science, Engineering \& Technology, 2(1), pp. 502-511.

13. Schaeffler Gruppe Industrie, 2009, Lager für Gewindetriebe, Katalog TPI 123D-D: Schaeffler Gruppe.

14. Deutsches Institut für Normung, 1994, DIN 732 Teil 1- Thermische Bezugsdrehzahl.

15. Deutsches Institut für Normung, 1994, DIN 732 Teil 2- Thermische Bezugsdrehzahl.

16. Krstić, V., 2013, Research limit speed of angular contact ball bearings (in Serbian), Master thesis, Faculty of Mechanical Engineering, University of Niš.

17. VDI-Geselschaft Verfahrenstechnik und Chemieingenieur Wesen, 2013, VDI-Wärmeatlas, Springer.

18. Deutsches Institut für Normung, 2004, DIN ISO 15312-Wälzlager- Thermische Bezugsdrezahl Berechnung und Beiwerte.

19. Heidenhain, 2006, Genauigkeit von Vorschubachsen, http://www.heidenhain.de/fileadmin/pdb/media / img/349843-10.pdf. 